\title{
A INFLUÊnCIA DE ANHAIA MELlo SOBRE O PENSAMENTO URBANÍSTICO EM SÃO PAULO: UMA ANÁLISE DOS PLANOS DIRETORES DO CENTRO DE PESQUISA E ESTUDOS URBANÍSTICOS
}

\section{Renata Monteiro Siqueira}

\section{Resumo}

Neste artigo, são analisados os planos diretores realizados pelo Centro de Pesquisa e Estudos Urbanísticos (CPEU), da Faculdade de Arquitetura e Urbanismo da Universidade de São Paulo. Anhaia Mello foi o principal idealizador e primeiro diretor desse Centro. Através dele, o urbanista teve oportunidade de aplicar os seus principais conceitos em torno do planejamento urbano. Dessa forma, confrontamos experiências práticas realizadas pelo CPEU com textos de autoria de Anhaia Mello e da própria instituição, sistematizando assim algumas ideias-chaves de seu pensamento urbanístico. Resgatando a historia do CPEU, assinalamos a sua influência sobre as experiencias de planejamento urbano que o sucederam, de modo a observar a constituição de um saber acerca do urbanismo formulado no âmbito da FAU-USP.

\section{Palavras-Chave:}

CPEU, Anhaia Mello, Planos Diretores.

\section{Abstract}

This paper analyzes the master plans developed for some cities from the State of São Paulo by the Centre for Research and Studies on Urbanism (CPEU), at the Faculty of Architecture and Urbanism of the University of São Paulo (FAU-USP). Anhaia Mello was its main founder and first director. Through the work that was developed at this research center, this planner had the opportunity to apply key concepts around urban planning which he had defended throughout his career. The practical experiments developed by CPEU were confronted to texts written by Anhaia Mello, in order to systematize some key ideas of his urban thought. One of the main goals of rescuing the history of CPEU is to point its influence on the experiences of urban planning that succeeded it, in order to observe the constitution of a knowledge about urbanism formulated within the FAU-USP.

\section{Keywords:}

CPEU, Anhaia Mello, Master Plans. 


\section{Introdução}

Neste artigo, analisamos os planos diretores desenvolvidos pelo Centro de Pesquisas e Estudos Urbanísticos (CPEU) da Faculdade de Arquitetura e Urbanismo da Universidade de São Paulo (FAU-USP). O CPEU foi criado pela lei que regulamentou a FAU-USP (lei no 3.233/1955), vinculado à Cadeira de Urbanismo, e iniciou seu funcionamento em 1957. Anhaia Mello foi seu diretor de 1957 a 1961, quando se aposentou. Após sua saída, o Prof. Lauro Bastos Birkholz dirigiu o Centro até o encerramento de suas atividades, nos anos 1970.

O CPEU inscreve-se em um momento da história do urbanismo de São Paulo marcado pela consolidação da categoria profissional dos arquitetos nas atividades de planejamento, a partir dos anos 1950. Os profissionais ligados a essa instituição atuaram na assistência técnica aos municípios paulistas, orientando a elaboração de planos e organizando o setor de planejamento no interior da estrutura administrativa (FELDMAN, 2005, p. 223). Não se tratou de um movimento isolado, mas inserido em um processo de institucionalização do campo de arquitetura e urbanismo, através da consolidação de sua entidade de classe - o Instituto de Arquitetos do Brasil -, de instituições de ensino, como foi o caso da FAU-USP, além de instituições de urbanismo externas às administrações, como a SAGMACS - Sociedade de Análise Gráfica e Mecanográfica Aplicada a Complexos Sociais. Para Feldman, tais instituições "atuaram na legitimação da atividade de planejamento, na difusão da ideia de plano geral para a cidade, na qualificação de profissionais urbanistas e na legitimação dos arquitetos no campo do planejamento urbano" (ibidem).

A análise dos planos foi feita observando os agentes que estiveram à frente da realização dos mesmos, bem como sua metodologia de elaboração. Confrontando os dados levantados com outros textos de Anhaia Mello e com a bibliografia existente ${ }^{1}$, buscamos identificar a influência do engenheiro-arquiteto sobre o pensamento urbanístico em são Paulo a partir da FAU-USP, faculdade da qual foi fundador, em 1948. Através da pesquisa, identificamos referências a trabalhos do CPEU desenvolvidos para 43 municípios paulistas entre 1957 e 1969. Dentre esses, acessamos os planos de: Santa Rita do Passa Quatro (1958); Águas da Prata (1958); Socorro (outubro/1959); Serra Negra (1961); São José dos Campos (plano de 1961, publicação de 1964); Itanhaém (agosto/1961); Pinhal (1965); Amparo (1966); Litoral

1 Para compreender as idéias de Anhaia Mello acerca do urbanismo e do Planejamento Urbano recorremos, principalmente, a Meyer (1990), Feldman (2005), Leme (2000), e Rolnik (1997) e Arasawa (1999). 
Norte (Ilhabela, Ubatuba, Caraguatatuba e São Sebastião, 1961), Presidente Prudente (1968); Bauru (1967); São José do Rio Pardo (1968); Igaratá (1968); Cubatão (1968) e Aparecida (1969). Portanto, analisamos documentos relativos a apenas dezoito dos municípios ${ }^{2}$. A ênfase, entretanto, é dada aos primeiros planos, elaborados sob a direção de Anhaia Mello (1957-1961).

\section{A criação do CPEU}

A lei n 3.233/1955, que instituiu o Regulamento da FAU-USP, previa, em seu artigo $6^{\circ}$, a Criação de um Centro de Pesquisa e Estudos Urbanísticos, anexo à Cadeira de Urbanismo do Curso de Arquitetura, sob a direção de seu professor. Segundo essa lei, o Centro destinava-se a:

I - a realizar pesquisas, análises e inquéritos preliminares à execução de Planos Urbanísticos parciais ou gerais; II - a organizar planos diretores para os municípios que o desejarem; III - a realizar planos e estudos relativos à habitação, uso da terra, regulamentos e programas; IV - à prática e exercício dos alunos da cadeira e do Curso de Urbanismo da Faculdade; e $V$ - à propaganda, educação e divulgação de forma a facilitar a solução de problemas urbanísticos.

$\mathrm{Na}$ visão de seus profissionais, pretendia-se estabelecer um vínculo entre universidade e sociedade, através da elaboração de atividades práticas de planejamento, que possibilitariam, por um lado, colaborar com a formação de planejadores e, por outro, produzir conhecimento teórico que subsidiasse o planejamento territorial em âmbito nacional (BIRKHOLZ \& NOGUEIRA, p.2). A partir de 1958, estabeleceu-se uma parceria entre o CPEU e o Departamento de Obras Sanitárias da Secretaria de Serviços e Obras Públicas do Estado de São Paulo (CPEU, 1963b, p.7), através da qual foram assinados convênios para a elaboração de Planos Diretores para as Estâncias Hidrominerais, Climáticas e Balneárias do Estado ${ }^{3}$.

As publicações do Centro revelavam uma preocupação com a divulgação de suas experiências práticas, como também de "propaganda"4 de ideias acerca do planejamento territorial. Além dos trabalhos práticos, o CPEU publicava Boletins

\footnotetext{
${ }^{2}$ Além dos planos aos quais tivemos acesso diretamente, também encontramos referência a trabalhos desenvolvidos pelo CPEU para os municípios de: Taubaté, Campos do Jordão, Atibaia, Santo André, Jaú, São Carlos, Osasco, Ribeirão Preto, Americana, Araraquara, Sorocaba, Limeira, Botucatu, Guaratinguetá, Pindamonhangaba, Caçapava, Mogi das Cruzes, Suzano, Franco da Rocha, São Roque, Bragança Paulista, Mogi Mirim, Catanduva e Franca.

${ }^{3} \mathrm{~A}$ justificativa para o planejamento desses municípios era o Decreto Estadual 28.399/1957, que regulava o sistema de dotações consignadas em favor desses tipos de estâncias (CPEU, 1963b, p.07).

4 "Propaganda" é a expressão usada pelos pesquisadores do CPEU. Arasawa (1999) chama a atenção para o fato de "a conquista da opinião pública" ser um elemento fundante na visão de urbanismo de Anhaia Mello. Nesse sentido, é possível reconhecer na preocupação do Centro a influência desse engenheiro-arquiteto.
} 
tratando dos fundamentos, da metodologia e de conceitos de planejamento territorial $^{5}$. Nessas publicações, observamos um esforço por justificar a importância do trabalho do CPEU, como é possível perceber no trecho abaixo:

(...) [O CPEU começou] desde logo, a desenvolver o seu programa de propaganda, educação e divulgação de ideias sôbre Urbanismo e orientando a organização de planos diretores para os municípios. (...) Entretanto, os problemas de planejamento territorial, pela sua evidente complexidade, exigiam soluções objetivas e satisfatórias. Os 435 municípios paulistas (...) estavam à espera dos trabalhos relativos à sua ordenação territorial. (...) 0 governo, levando em conta o alto interesse público que poderia representar a ordenação do território desses municípios, planejamento esse que, como é óbvio, traria indiretamente grandes benefícios para o próprio Estado, houve por bem estabelecer um programa, a fim de atender a esse objetivo. $E$ ao defini-lo, sabiamente, procurou entrosar a cultura, representada pela Universidade com a técnica, na Secretaria de Viação e Obras Públicas (CPEU, 1960a, p.2).

\section{As ideias de Anhaia Mello}

O primeiro Boletim do CPEU, "Elementos para o planejamento territorial dos municípios" $^{\prime 6}$, é de autoria de Anhaia Mello. Nesse texto, é feita uma defesa do Plano Diretor e uma apresentação dos procedimentos para sua elaboração. Também estão presentes algumas de suas principais ideias acerca de seu ideal de cidade. O Boletim se configura como um manual de referência para elaboração de Planos, balizando a metodologia dos planos do $\mathrm{CPEU}^{7}$, que descreveremos adiante.

Anhaia Mello falava em "planejamento municipal", contemplando os meios urbano e rural. Inspirado na cidade-jardim de Howard e, principalmente, na sua versão norte-americana (FELDMAN, 2005, p. 127), o urbanista defendia a cidade finita, "completa, acabada, obra de arte" (CPEU, 1963a, p. 17). Crítico das metrópoles "congestionadas", de crescimento "ilimitado", afirmava que o tamanho ótimo de

\footnotetext{
${ }^{5}$ Foram publicados 18 "Boletins do CPEU": "Elementos para o Planejamento Territorial dos Municípios" (1963)," Organização Comunitária", "Do Planejamento e suas Fases", "Anteprojeto de lei de loteamento e respectivas normas técnicas", "Documentos sobre organização comunitária", "Zoneamento: classificação dos usos do solo", "O CPEU da FAU-USP e os convênios realizados para o planejamento das estâncias do Estado de São Paulo", "O processo de planejamento territorial", "Problemas legais relacionados com o planejamento municipal - v.I", "Conselho de desenvolvimento, escritório técnico de planejamento e departamento de obras", "Reorganização dos serviços tributários dos municípios", "Problemas legais relacionados com o planejamento municipal - v.II", "Problemas de Planejamento Habitacional", "Problemas legais relacionados com o planejamento municipal - v.III", "Legislação sobre loteamento", "Roteiro para o planejamento do litoral norte do estado de São Paulo", "Processo para implantação de planos municipais", "Uma experiência de participação comunitária para o planejamento".

${ }^{6}$ Apesar de editado em 1963, a sua publicação original se deu em 1957, coincidindo com o início das atividades do CPEU.

7 A referência a Anhaia Mello era explicitada nos registros do processo de planejamento, como se observa, por exemplo, na citação: "a palestra do Prof. Anhaia Mello constitue um roteiro para o planejamento territorial das Estâncias Balneárias de São Sebastião, Ilhabela, Caraguatatuba e Ubatuba" (Boletim Informativo para o Planejamento Territorial do Litoral Norte, $\mathrm{n}^{\circ} 4,1960$ ).
}

URBANA, V.5, nº6, mar.2013 - Dossiê: Urbanistas e Urbanismo- CIEC/UNICAMP 
população de uma cidade deveria estar compreendido entre 30 mil e 100 mil habitantes (idem, p.12), delimitando a área urbana através de um cinturão verde (idem, p.18). O crescimento se daria no âmbito regional, através de uma rede de cidades pequenas ou médias. O autor afirmava que:

Não se mede pelo tamanho, nem pelo número de habitantes, nem pela cifra do orçamento municipal, o valor real de um núcleo urbano-rural para a vida feliz dos seres humanos. Mede-se pelo standard de vida, elevado, generalizado, seguro, dos seus habitantes; pelo índice de integração moral e social que o caracterize. (CPEU, 1963a, p.12)

Embora Anhaia Mello enfatizasse o fator qualitativo do planejamento territorial e do valor das cidades, diante do caráter quantitativo das suas propostas para alcançar esse "standard de vida elevado", pautado em índices demográficos e de ocupação do solo, trata-se efetivamente de uma questão numérica, pois de seus textos infere-se não ser possível alcançar um padrão de vida adequado em uma cidade densamente ocupada ou com grande número de habitantes.

Os instrumentos de planejamento apontados pelo engenheiro-arquiteto são referentes aos princípios do urbanismo modernista ${ }^{8}$. 0 primeiro deles era 0 zoneamento $^{9}$, que viabilizaria a cidade funcional (macrozoneamento) e o estabelecimento de índices construtivos diferenciados por setores (microzoneamento ou zoneamento diferencial), interligados pelos meios de transporte e comunicação. Os usos urbanos deveriam estar próximos, mas não misturados: "é um problema de ordem; um lugar para cada coisa e cada coisa no seu lugar" (CPEU, 1963a, p.18). Esse instrumento visava proteger o "bem comum" de interesses privados. Como exemplo, o autor citou a necessidade de "proteger a residência isolada, térrea ou de sobrado, contra a intromissão indébita dos de residência coletiva ou apartamentos, que vão roubar o sol, o arejamento, a boa iluminação natural, o sossego, a privatividade das residências isoladas" (idem, p. 19).

Também a localização das indústrias era um tema relevante. Defendia a desconcentração das indústrias para além das Regiões Metropolitanas e, no espaço intra-urbano, apoiado em um "Coeficiente de Nocividade ou Distúrbio", defendia que indústrias não incômodas se localizassem nas bordas das Unidades de Vizinhança, em

\footnotetext{
${ }^{8} \mathrm{~A}$ última parte do Boletim do CPEU $\mathrm{n}^{\circ} 1$ é uma recapitulação das regras de boa ocupação do solo apontadas por Le Corbusier em Propos d'Urbanisme (1946), tais como: adoção de uma escala humana, "satisfazer a reivindicação: sol, espaço, verde"; fixar a relação entre área livre e área construída; fixar as densidades; e admitir a limitação das aglomerações, fixando o perímetro máximo da cidade.

${ }^{9}$ No Boletim do CPEU n 6, "Zoneamento: classificação dos usos do solo urbano" é apresentada uma lista detalhada de tipos de uso do solo, sob a justificativa de subsidiar o processo de planejamento.
}

URBANA, V.5, nº6, mar.2013 - Dossiê: Urbanistas e Urbanismo- CIEC/UNICAMP 
bloco e junto às vias principais, que indústrias pesadas fossem situadas em zonas específicas e que as perigosas se instalassem fora da área urbana (idem, p. 24).

O segundo instrumento presente no escopo do planejamento defendido por Anhaia Mello era a Unidade de Vizinhança, que para o urbanista consistia na "base estrutural das cidades", prestando-se a promover sua "saúde social". Ela garantia assim o espírito comunitário e a vida familiar, por uma disposição mais conveniente à atividade da vida cotidiana (idem, p. 34). Ainda inspirado no urbanismo modernista, defendia as superquadras sob a justificativa da redução da possibilidade de acidentes com automóveis, com menos cruzamentos. Cada superquadra, com 1000 pessoas, consistia numa "unidade residencial", dotada de determinados equipamentos sociais. A unidade de vizinhança constituir-se-ia num agrupamento de dez superquadras (10.000 pessoas), que deveria possuir outros equipamentos coletivos, além de um centro comercial. A cidade, reunião de entre 5 e 15 unidades de vizinhança, teria além desses diversos centros e equipamentos, o centro principal, "cívico, administrativo, cultural e de negócios". O controle da densidade demográfica se justificava pelo adequado dimensionamento da população residencial a ser atendida pelos serviços de utilidade pública, pelas vias de comunicação e pelos transportes coletivos.

Por fim, Anhaia Mello defendia a polinucleação, com a hierarquização de centros no espaço intra-urbano, que iriam desde o centro principal aos secundários, relativos às unidades de vizinhança, unidades residenciais até o centro dos "lares individuais - a sala comum ou 'living'" (CPEU, 1963a, p.29). Trata-se do que ele chamava de "cidade em cacho" em vez de "cidade em alvo" (idem, p.34). A polinucleação seria produzida através da constituição das Unidades de Vizinhança. Nas publicações do CPEU, afirmava-se que essas constituíam princípios "universalmente aceitos segundo os quais as cidades devem ser planejadas como organismos polinucleados, com diversos centros e sub-centros urbanos, visando uma maior racionalidade na distribuição dos equipamentos sociais nos bairros" (CPEU, 1964a, p. 21).

O resultado do processo de planejamento seria o alcance de um equilíbrio entre os quatro meios com os quais o homem se relaciona ("primevo", rural, urbano e metropolitano), entre as funções da vida humana (trabalho, recreio, habitação e circulação) e entre os ritmos humano (de 4 km/h) e mecânico (de 100 km/h a velocidades supersônicas). Na noção de equilíbrio reconhecemos a visão de cidade de Anhaia Mello, calcada numa cidade finita, obra acabada, distinta ainda que próxima do campo e do verde, funcional e articulada por sistemas de circulação hierarquizados e de comunicação. 
Repetidamente o autor ressaltou o caráter cívico da cidade e o papel do planejamento de corrigir os problemas que ele identificava com a perda de interesse pelo coletivo. Anhaia Mello enfatizava o objetivo "humano e social" do planejamento, visando, portanto, o interesse coletivo. Isso nos coloca um problema, visto que há que se buscar compreender a que, ao certo, ele se referia ao mencionar o "interesse coletivo". Esse interesse é limitado pelo caráter "politicamente neutro" atribuído por ele ao processo de planejamento: "planejamento, como qualquer técnica, é politicamente neutro; há um processo, pois, que deve ser seguido por todos, para acertar" (MELLO, 1945). Os argumentos a partir dos quais ele justificou a importância do planejamento, como a "felicidade geral" e o "bem comum" não são definidos por ele. Configuram, contudo, um discurso facilmente reprodutível, na medida em que cada um pode atribuir-Ihes o significado que desejar. Trata-se de interessante artifício de conquista da opinião pública - preocupação constante no seu trabalho- visto que, por terem um significado vago e abrangente, podem modelar-se plasticamente segundo os interesses e a ótica de quem os interpreta. Ao mesmo tempo, trata-se de um argumento facilmente refutável. A análise feita por Feldman (2005) sobre as implicações da implantação do zoneamento em São Paulo, fortemente influenciada pelas ideias de Anhaia Mello, revelou que este tendeu a preservar os valores dos imóveis em um determinado setor da cidade - o vetor sudoeste, ocupado pelas elites - e isso não estaria a serviço do favorecimento do "bem comum" em um sentido mais amplo, mas sim a serviço dos interesses de uma determinada classe social. A sua definição de "bem comum" sinaliza os seus próprios limites, uma vez que se tratando do "maior bem para o maior número, eis que seria difícil - se não impossível realizar o bem total de todos" (CPEU, 1963, p. 13), perspectivas de transformações mais estruturais da sociedade ficaram excluídas.

Para situar Anhaia Mello em um lugar mais complexo no âmbito do debate urbanístico paulistano, acreditamos que seja pouco significativo buscar aprofundar o sentido do que seria a "felicidade geral", bem como insuficiente entender sua visão de urbanismo restrita à crítica e recusa da metrópole industrial, aos princípios da cidadejardim, ao zoneamento e aos parâmetros de uso e ocupação do solo. Nesse sentido, é importante a interpretação de Arasawa (1999). Este pesquisador situa os princípios urbanísticos do engenheiro-arquiteto no âmbito de um discurso cuja finalidade era posicioná-lo em um determinado lugar de poder.

\section{A metodologia de trabalho nos planos do CPEU}


Segundo Anhaia Mello, o planejamento constituía-se na ordenação e equipamento do espaço coletivo, apresentando-se como "o antídoto para os males do fracionamento do mundo moderno" (CPEU, 1963a, p. 8). Tratava-se, assim, de um processo abrangente e unificador que visava estabelecer o equilíbrio entre "Povo, Território e Economia"10 (ibidem). Ele enfatizava também o caráter preventivo do Plano, e não corretivo, "antecipando o próprio desenvolvimento, e promovendo medidas adequadas para que áreas, funções, estruturas e equipamentos se harmonizem e se integrem, sem disperdícios (sic), dificuldades ou sofrimentos futuros" (ibidem), bem como o seu caráter "positivo", ou seja, não apenas impondo restrições e servidões aos particulares, mas também "criador".

Com relação aos procedimentos do processo de planejamento, em "Elementos para o planejamento territorial dos municípios", Anhaia Mello apontou as seguintes fases:

1) Fixação do objetivo; fase inicial;

2) Inquéritos e pesquisas, para identificação das necessidades, em função do estado atual e das tendências, e coleta de dados essenciais relativos ao Sítio e ao Homem.

3) Plano Diretor ou Regulador, que determina, de maneira geral e programática, as linhas mestras do desenvolvimento; procedido em regra por um Pré-plano ou Plano Pilôto, esboço de linhas gerais, realizado de acordo com os dados existentes e um primeiro contato global;

4) Planos Executivos, detalhados e minuciosos, englobando obras a realizar, em períodos sucessivos de 5 anos, de acordo com a ordem de urgência e as possibilidades financeiras;

5) Problema educativo e de realização, para formação do que se chama a consciência urbanística da população, para conjugação de vontades e esforços no sentido do Bem Comum (CPEU, 1963a, p.14), grifos do autor.

O Plano Diretor deveria contemplar os sistemas gerais de vias principais, zoneamento e espaços livres verdes e os problemas específicos de desenvolvimento local e organização comunitária. Com relação a este último item, entendia-se como "organização comunitária" a constituição da Comissão do Plano ${ }^{11}$, que devia ser aprovada em lei municipal. Esse órgão consultivo era responsável por estabelecer o

\footnotetext{
${ }^{10}$ No entanto, citações como esta: "comido pelo micróbio o caiçara integra uma população mais valiosa como material clínico do que como força econômica" (CPEU, 1974, p. 4.2) sugerem que podia haver uma ênfase sobre o fator econômico. No discurso havia uma harmonia entre os três elementos, mas do ponto de vista prático, o argumento era econômico.

11 Feldman (2005), Leme (2000) e Arasawa (1999) assinalaram a influência norte-americana nos procedimentos de planejamento adotados por Anhaia Mello. A Comissão do Plano é uma expressão direta disso. Segundo Feldman, o CPEU foi "um verdadeiro laboratório para as ideias americanas difundidas por Anhaia Mello. Em relação à organização do planejamento, as propostas se mantêm fiéis à estrutura de uma comissão com representantes da sociedade articulada ao órgão municipal. Formam-se, nas cidades do interior paulista, comissões com função staff e equipes multidisciplinares, aglutinando especialistas de outras áreas do conhecimento... da USP ou das cidades objeto dos planos" (2005, p.226).
} 
diálogo entre o órgão técnico e o restante da sociedade. A designação era feita pelo poder público, pelos órgãos de classe e outras associações, o que restringia o alcance da participação popular.

O processo de ordenação territorial deveria ser desenvolvido em três etapas. Na primeira, seriam delimitados o "grid" circulatório (sistema de vias principais) e as "Green-belts". Na segunda seria desenvolvido o macrozoneamento e na terceira o microzoneamento, bem como o detalhamento da estrutura interna das unidades resultantes desse processo e de seu equipamento.

A realização de trabalhos práticos a partir dessas ideias foi viabilizada por meio de uma articulação entre o CPEU, o Governo do Estado, através do Departamento de Obras Sanitárias, e dos municípios, com a criação de um convênio para a realização de Planos Diretores municipais. Os primeiros convênios foram firmados com Estâncias Hidrominerais, Climáticas e Balneárias. Em seguida, o convênio estendeu-se para outros municípios. Foram realizados diferentes tipos de contratos, que envolviam desde a condução de todo o processo pelo CPEU até a prestação de assistência técnica às Prefeituras Municipais (BIRKHOLZ \& NOGUEIRA, 1992, p. 8).

Nos convênios realizados, eram estabelecidas as responsabilidades das partes. A obtenção de recursos e de imagens aéreas atualizadas era incumbência do Departamento de Obras Sanitárias. Previa-se também a designação ou contratação pela Prefeitura Municipal de um arquiteto para elaboração do plano, sob orientação do CPEU, residindo no local, bem como a contratação de pesquisadores e técnicos especializados para subsidiar o trabalho do CPEU (CPEU, 1963b, pp.8-9). O processo de planejamento costumava ser iniciado com uma palestra do diretor do CPEU voltada para o poder público e os outros agentes envolvidos na realização do plano. Nessa palestra, Anhaia Mello sintetizava suas principais ideias acerca do planejamento, reproduzindo boa parte do conteúdo de seus textos, notadamente o Boletim $\mathrm{n}^{\circ} 1$ do CPEU e "O Plano Regional para São Paulo". Essa palestra era apontada pelo CPEU como um "roteiro" para a realização do planejamento territorial do município em questão (CPEU, 1960d, p.1).

A primeira fase do processo denominava-se "fase de eclosão e preparação de elementos básicos para o planejamento". Nessa fase eram reunidos os dados existentes sobre o município, notadamente as informações cartográficas e dados estatísticos, pesquisa bibliográfica sobre os problemas dos municípios, além da realização do "Cadastro" dos imóveis e equipamentos urbanos e rurais. Nesse momento também se constituíam a Comissão do Plano e a Comissão Técnica, "órgão 
de planejamento", composta por um engenheiro ou arquiteto responsável pela elaboração do plano e por uma equipe multidisciplinar. A questão da multidisciplinariedade, com pesquisadores universitários ou pertencentes ao município objeto do plano, era reiterada em diversos momentos nas publicações do CPEU: "reunindo especialistas de outros institutos universitários o Centro está não só promovendo a formação do verdadeiro espírito universitário, como também beneficiando-se da contribuição valiosa para o desenvolvimento e aperfeiçoamento de planejamento territorial" (CPEU, 1960a, p.4). Ao final dessa fase, o planejador já podia prever "a programação de algumas obras públicas" (CPEU, 1960a, p.7).

A segunda fase, intitulada "fase de projeto", era desenvolvida em quatro etapas. A primeira, "Contacto Global", consistia num reconhecimento da área através de uma visita de campo, subsidiando uma análise que levaria à realização da segunda etapa, o "Plano Preliminar". Esse plano, uma primeira síntese, contemplaria a definição do macrozoneamento (relativo às funções), do sistema de vias principais e terminais regionais, da indicação de áreas para usos institucionais e da legislação sobre outros assuntos ligados ao desenvolvimento municipal. A terceira etapa, "Pesquisa e Análise da Realidade e das Possibilidades Municipais" consistia na realização do trabalho da equipe de especialistas, visando "os aspectos físicos e humanos da região". Os aspectos físicos subdividiam-se nos relativos à natureza e à ação humana, e os aspectos humanos em aspectos de ordem histórica, demográfica, econômica, social, financeira, administrativa, política e legal. Cada item de pesquisa era desenvolvido por uma equipe sob coordenação de um profissional (em geral professor da USP). Eram realizadas visitas de campo ${ }^{12}$ e reuniões de equipe e produzia-se um relatório a ser analisado pelo CPEU. A quarta etapa da "Fase de Projeto" consistia na redação do plano diretor, composto por uma memória descritiva e justificativa, constando de duas partes, uma para a zona urbana e outra para a zona rural, conforme estabelecido por Anhaia Mello no Boletim do CPEU nº 01.

Finalmente, a terceira fase de planejamento correspondia à execução da intervenção prevista no plano diretor. Isso se dava mediante a elaboração de Planos Executivos quadrienais ou quinquenais e de programas de obras anuais. Também devia ser elaborado um código urbanístico municipal contemplando leis de loteamentos, zoneamentos e obras, bem como a reorganização da administração municipal através da institucionalização da "organização comunitária"13, a instituição

12 Os modelos dos materiais utilizados para o levantamento de campo foram compilados em um documento intitulado "Modelos de fichas de levantamento e organização de dados para elaboração de Planos Diretores Municipais", de 1959 (mimeo).

${ }^{13}$ Defendia-se que a "Comissão do Plano" devia ser transformada em um "Conselho de Desenvolvimento" ligado à administração municipal.

URBANA, V.5, n6, mar.2013 - Dossiê: Urbanistas e Urbanismo- CIEC/UNICAMP 
de um "Serviço de Ação Comunal", a coordenação de obras públicas federais, estaduais e autárquicas do município e, por fim, a atualização periódica do plano diretor.

\section{A equipe do CPEU}

Os dois principais gestores do CPEU foram Anhaia Mello, seu fundador e primeiro diretor, de 1957 a 1961, e Lauro Bastos Birkholz, diretor de 1962, quando assumiu também a Cadeira de Planejamento $\mathrm{II}^{14}$, a 1976. Antes de dirigir o CPEU, Lauro Birkholz tinha o papel de "Coordenador entre o Departamentos de Obras Sanitárias da Secretaria da Viação e Obras Públicas e o CPEU"15, uma posição importante, se considerarmos a relevância da relação estabelecida entre esses dois órgãos para a sobrevivência e legitimação do centro de pesquisa. Lauro Birkholz e Brenno Cyrino Nogueira, arquiteto formado pela FAU-USP em 1958, também fizeram um esforço pela manutenção da memória do CPEU durante a sua existência e também após a sua extinção, através da produção de textos de divulgação e reedição de trabalhos realizados. Durante a gestão de Anhaia Mello, Nogueira trabalhou no Escritório Técnico de Planejamento de São José dos Campos, ao lado dos arquitetos Flávio A.S. Reis e Sidney Antonio do Amaral, em colaboração com a Comissão Técnica. Na gestão de Birkholz, foi Professor Adjunto da Cadeira de Planejamento e Chefe Técnico-Administrativo do CPEU.

O CPEU organizou uma equipe de especialistas para a elaboração dos vários planos. Durante a gestão de Anhaia Mello, contava-se com uma Equipe de Planejamento, constituída por seu coordenador, o Engenheiro Rubens Mattos Pereira, e pelos Arquitetos Marianilza Brasil de Oliveira e Milton Carlos Ghiardini ${ }^{16}$. Havia também uma Equipe de Pesquisadores, responsável pela realização da pesquisa que deveria subsidiar o processo de planejamento, e que contou com a participação dos arquitetos Celso Lamparelli, Domingos Theodoro de Azevedo Netto, José Arnaldo Pittom e Maurício Rosembaum. Esses pesquisadores haviam trabalhado também na Sociedade de Análises Gráficas e Mecanográficas Aplicadas aos Complexos Sociais SAGMACS.

\footnotetext{
${ }^{14}$ Após a Reforma de Ensino de 1962, a Cadeira de Urbanismo foi dividida em Cadeira de Planejamento I e Planejamento II. O CPEU passou a vincular-se a esta cadeira (CPEU, 1963b, p. 5).

15 Nos Planos Diretores publicados pelo CPEU, o nome cargo de Lauro Birkholz variava, mas o sentido do cargo costumava ser esse, de ponte entre os dois órgãos. O convite a Birkholz para integrar o CPEU foi feito por Anhaia Mello em 1957, quando ele ocupava o cargo de Diretor de Planejamento do Departamento de Obras Sanitárias (BIRKHOLZ \& NOGUEIRA, 1992, p.5).

16 Os planos de Itanhaém e dos municípios do Litoral Norte também contaram com a Arquiteta Rita Olmo. Sem ter a pretensão de listar todos os membros do CPEU, reproduzimos neste artigo os nomes relacionados nos planos de diversos municípios, considerando que esses fizeram parte de um processo mais abrangente e não participaram apenas de casos pontuais.
} 
Além disso, especialistas eram responsáveis por desenvolver aspectos específicos: o economista Luiz Fernando Pereira Vieira elaborou em alguns planos os "Aspectos Econômicos"; os "Aspectos Administrativos" ficaram a cargo do economista Joaquim da Rocha Penteado. A Equipe de Legislação Urbanística era composta pelos juristas Hely Lopes Meirelles ${ }^{17}$, Cyro Laudano Filho e Genaro Tavares Guerreiro. Os "Aspectos Sociais" ficaram a cargo da Socióloga Marisa de Assis. Gustavo Neves da Rocha Filho, que após a aposentadoria de Anhaia Mello tornou-se o coordenador dos Planos Diretores realizados pelo CPEU, trabalhou os "Aspectos Históricos" do Plano de São José dos Campos e assessorou Rubens de Mattos Pereira na coordenação do planejamento dos municípios do Litoral Norte. Relativamente ao período que se sucedeu à aposentadoria de Anhaia Mello, é interessante observar o título atribuído a Gustavo Neves da Rocha Filho: em 1965, no Plano de Pinhal, ele aparece como "Urbanista e Arquiteto", invertendo a denominação usual de "Arquiteto e Urbanista". Em seguida, no Plano de Amparo (1966) ele será apresentado apenas como "Urbanista".

\section{Os planos realizados pelo CPEU}

Consultamos os planos realizados sob a direção de Anhaia Mello para os seguintes municípios: Santa Rita do Passa Quatro, Socorro e São José dos Campos, que tiveram convênio firmado em abril de 1958; Caraguatatuba, Ubatuba, São Sebastião e Ilhabela, com convênio de maio de 1958; Itanhaém (convênio de novembro de 1960). Também acessamos os seguintes planos desenvolvidos sob a gestão de Lauro Birkhoklz: Pinhal, Amparo, Cubatão, Aparecida, Igaratá.

Em todos os casos, os planos estiveram balizados em uma análise econômica e demográfica. Por um lado, observava-se a "vocação econômica" do município (industrial, turística, etc) e fazia-se uma análise da população existente e a previsão de crescimento em um horizonte de aproximadamente 30 anos. Estimava-se uma população máxima para o município considerando que, na medida do possível, o ciclo de crescimento cessaria e finalmente a cidade se tornaria "obra acabada". Em função da população existente e prevista, propunha-se um plano de expansão, calculava-se o estoque de áreas vazias necessárias para abrigar toda a população, mediante a ocupação dos vazios urbanos em detrimento do "loteamento prematuro da área rural". Também era dimensionada a demanda por equipamentos públicos e os planos dispunham sobre a localização dos mesmos. Sintetizando o produto desses planos, definia-se o perímetro urbano e de expansão urbana, a população máxima do

\footnotetext{
17 Hely Lopes Meirelles também organizou três volumes de Boletins do CPEU ( $n^{\circ} 9,13$ e 14) intitulados
} "Problemas legais relacionados com o planejamento municipal", publicados entre 1963 e 1966. 
município, o zoneamento (micro e macro), propunha-se os setores residenciais e suas normas de ocupação, bem como traçado do sistema viário.

Os primeiros planos realizados pelo CPEU apresentavam a seguinte estrutura: na introdução, fazia-se uma defesa da importância do planejamento e resgatava-se o histórico do convênio firmado entre o CPEU, a prefeitura e o Departamento de Obras Sanitárias. Em seguida eram apresentados os "Elementos preliminares do Plano", em que se descrevia o processo de constituição das comissões e a reunião de documentos. Também nesta seção descrevia-se o Plano Piloto, com a apresentação do zoneamento proposto, a delimitação do perímetro urbano, os principais parques e áreas verdes e sistema viário principal. Em seguida, passava-se à "Pesquisa", abordando os aspectos físicos (clima, geologia, hidrografia), socioeconômicos ("possibilidades de utilização humana", população, atividades econômicas, comunicação, equipamentos, finanças públicas) e urbanísticos (funções, habitação, espaços livres, monumentos históricos e sítios pitorescos, legislação, uso do solo). Após a apresentação da pesquisa, passava-se aos "Fundamentos do Plano", em que eram apontadas as diretrizes para o desenvolvimento do município. Por fim, era apresentada a "Composição do Plano", dividida em "Zona Rural", visando melhorar as condições de produtividade e propondo como solução a criação de Centros Comunitários Rurais, e "Zona Urbana". Nessa seção, enfatizava-se a importância de se fixar o perímetro das cidades, evitando o "loteamento prematuro de glebas rurais" e dimensionando os equipamentos públicos; propunha-se a setorização e criação de unidades de vizinhança (bairros ordenados e equipados). O Estudo era concluído com um capítulo intitulado "Continuação do Processo de Planejamento", em que era apontada a organização de um Cadastro de Imóveis e de Equipamentos Básicos, visando a "racionalização administrativa" a fim de facilitar lançamentos fiscais e desapropriações. Também eram tratados os Instrumentos para Execução do Plano. Do ponto de vista do controle das atividades privadas de loteamentos e edificações, mencionava-se: o Código de Zoneamento (delimitar os usos de cada lote urbano), Código de Loteamento (controlar e ordenar os novos loteamentos visando constituir bairros organizados), Código de Obras (ditar as características de cada nova construção) e um Regulamento de Zoneamento (delimitar as áreas para os diversos usos definidos no código de zoneamento). Do ponto de vista do poder público, propunha-se a Programação das Obras Públicas através de Planos Executivos para cada mandato de Prefeito. É curioso também observar que em diversos planos foi feita a defesa de um sistema viário de fundo de vale, sob o nome de "avenidas parque", compreendido como uma forma de preservar os rios. 
Sempre era enfatizada a importância de realizar um planejamento em escala regional. Desse modo, por exemplo, no plano de São José dos Campos sugeriram um plano para o Vale do Paraíba, no caso de Socorro o estudo propunha a realização de um plano abrangendo também Águas de Lindoia, Serra Negra e Amparo. Sugeriram a realização de um Plano para o Litoral Norte englobando os municípios de Caraguatatuba, Ubatuba, São Sebastião e Ilhabela, e assim por diante. Cabe observar que em geral o CPEU adotou a divisão regional proposta pelo estudo da SAGMACS "Problemas de desenvolvimento - Necessidades e possibilidades do Estado de São Paulo" de 1954, realizado para a Comissão Interestadual da Bacia Paraná-Uruguai, em detrimento de outras subdivisões existentes, como a do IBGE. Em 1967, o CPEU apresentou o Plano de Regionalização do Estado de São Paulo para o Governo do Estado.

Os planos realizados para as Estâncias apresentavam preocupações relativas ao turismo. Assim, para Socorro ou Santa Rita do Passa Quatro, por exemplo, levantaram-se os atrativos com potencial turístico e espaços verdes, propondo-se a criação de parques regionais. O plano apresentava também medidas tidas como necessárias para a viabilização do município como pólo turístico (zona hoteleira, proteção e valorização dos recursos naturais, acessibilidade, artesanato e comércio). Para os municípios litorâneos havia também uma preocupação com o aumento de população sazonal.

O trabalho compreendia um "plano rodoviário municipal", prevendo a conservação e retificação do sistema viário existente. Em geral, era proposto um sistema perimetral (rural) interligando os centros comunitários previstos no plano e desviando o volume de tráfego do centro da cidade. As áreas residenciais eram organizadas em Unidades de Vizinhança. No centro da cidade, o coeficiente de aproveitamento era mais elevado que nas outras zonas urbanas, permitindo-se também a convivência de usos comerciais e residenciais. O estudo para o zoneamento levantava também problemas pontuais prevendo, quando fosse o caso, soluções de longo prazo, como se observa no caso de Santa Rita do Passa Quatro, em que se identificou como um problema a edificação de uma maternidade e da Santa Casa de Misericórdia em uma "zona residencial", que, segundo a avaliação feita, teria "seu funcionamento prejudicado, tornando-se inconveniente sua localização" com o processo de crescimento da cidade. A solução apontada, neste caso, foi reservar uma área "um pouco afastada do centro, destinada à zona hospitalar para onde convergirão outras instituições que se localizarem no Município e para onde se deslocarão as instalações já existentes" (CPEU, 1959b, p. 26). Em todos os casos 
também era estudada a localização da zona industrial, na medida do possível junto às rodovias e também tendo em vista "os ventos dominantes", um critério que visava diminuir os incômodos para as zonas residenciais. Com frequência, a proposta de uma determinada medida se justificava numa "tendência natural" de localização, por exemplo, de um centro comercial, uma zona industrial ou residencial. Do ponto de vista da qualidade das moradias, fazia-se uma classificação em função de tipos aparentes, em "irrecuperáveis", "casas populares a completar infraestrutura", "casas médias, equipadas e confortáveis" e "casas luxuosas".

O plano apresentava três cartas propositivas. A primeira, em escala regional, se referia ao sistema viário, articulado com pontos turísticos e ambientais (reserva florestal). A segunda continha as obras viárias e de canalização na escala da cidade. Por fim, apresentava-se um mapa de zoneamento para as áreas rural e urbana.

O Plano de São José dos Campos foi concluído em 1961. Neste caso, havia uma preocupação com o processo de industrialização do município. De acordo com o Plano Preliminar, sua elaboração foi marcada pelas etapas de: fixar o perímetro das zonas urbana e de expansão urbana, com a delimitação dessa expansão "com base em previsões econômico-demográficas"; estabelecer o zoneamento de massas; a divisão das zonas residenciais em setores ("distritos") e unidades de vizinhança ("bairros"), passando-se para a proposição do sistema viário, baseado em avenidas de fundo de vale ou "avenidas-parque", que deveriam proteger os cursos hídricos.

O processo foi acompanhado pela elaboração de uma legislação urbanística, da qual se destaca: o Decreto $n^{\circ}$ 250/1958, um "zoneamento de massas" que fixava uma zona industrial ao longo da Rodovia Dutra e interditava a instalação de indústrias incômodas em determinadas áreas; o Decreto n²86/1959, que definia o perímetro da zona urbana do município; a lei n 657/1960 e o decreto n 332/1960, estabelecendo as condições mínimas de infraestrutura urbana para a aprovação de loteamentos; e a lei n664/1960, estabelecendo coeficientes de aproveitamento de lotes, gabaritos máximos, dentre outros parâmetros (o chamado "zoneamento diferencial"), "de modo a propiciar uma densidade residencial adequada ao município" (CPEU, 1964, p. 3). Esta última lei foi baseada na Lei $n^{\circ} 5.261 / 1957$ do município de São Paulo, havendo apenas alterando-se apenas os valores, como o Coeficiente de Aproveitamento, fixado em 4 para edifícios comerciais e 2 para prédios residenciais, ao passo que em São Paulo esses eram, respectivamente, 6 e 4, e a "densidade residencial líquida" máxima de $500^{18}$ ao invés de 600 habitantes por hectare. Em 18/02/1960 a lei foi derrogada por iniciativa da Câmara de Vereadores do município.

\footnotetext{
18 No Plano Preliminar, contudo, foi determinada uma densidade "ótima" entre 200 e 300 habitantes/ha
} (CPEU, 1964, p.29). 
Sobre isso, o CPEU manifestou-se afirmando que: "a lei de zoneamento referente à área central da cidade sanará as lacunas surgidas com êsse ato e está destinada a preencher de forma mais eficiente as necessidades daquela área referente ao zoneamento" (1964a, p.19). Relativamente à legislação aprovada, Dr. Hely Lopes Meirelles, que trabalhou na equipe responsável por sua elaboração, afirmou: "Quebrou, assim, o município de São José dos Campos o tabu da regulação de loteamentos, que até bem pouco era considerada, errôneamente, de exclusiva competência federal"19 $^{1 \mathrm{C}}$ (CEU, 1964a, p.17). Após o final do processo de elaboração do plano, a Comissão do Plano Diretor foi transformada em "Conselho de Desenvolvimento". Essa experiência foi também registrada no Boletim n 10 do CPEU, que tratava da criação de órgãos de planejamento (CPEU, 1963c). O processo de planejamento de São José dos Campos foi considerado bem sucedido pelos seus realizadores, como atesta a fala de Lauro Birkholz: "O planejamento de São José dos Campos marcou uma nova experiência nos métodos de trabalho do CPEU: realização de estudos e pesquisa por meio de equipe polivalente, com profissionais especializados nos diversos ramos de conhecimento necessários ao planejamento" (BIRKHOLZ, 1964).

O planejamento dos municípios do Litoral Norte despertou o interesse dos pesquisadores do CPEU por se tratar de uma possibilidade concreta de realização de um planejamento regional, tal como defendiam: "Pela primeira vez vai o Centro de Pesquisa e Estudos Urbanísticos reunir ao mesmo tempo equipe de especialistas os mais variados e quatro municípios que, juntos, definem uma região com características próprias, como é o caso dêste Litoral Norte" (CPEU, 1960a, p. 4). Nas palavras de Anhaia Mello, "os planos regionais não são super planos, mas planos de coordenação, que asseguram a harmonia entre os grandes planos econômicos, de um lado, e os programas técnicos, de outro... São planos estruturais estabelecendo a orientação e as limitações dos planos municipais e urbanos" (CPEU, 1960d, p.4)

No entanto, alguns anos mais tarde, esses pesquisadores reconheceram que o processo não resultou em um plano regional integrado, mas num conjunto ou uma série de quatro planos preliminares municipais. Muitos aspectos não puderam ser abordados em uma escala verdadeiramente intermunicipal, especialmente o sistema viário e os usos do solo na faixa litorânea (CPEU, 1960a, p. 5). Embora o plano preliminar desses municípios tenha sido concluído no início dos anos 1960, o processo de planejamento foi retomado após as enchentes de 1967 em Caraguatatuba. Os planos preliminares seguiram a mesma orientação dos outros planos realizados no

${ }^{19} \mathrm{Em}$ artigo "Digna de imitação a legislação urbanística de São José dos Campos" publicado na coluna "Assuntos Municipais" do jornal Folha de São Paulo, de 15/01/1961. 
período, voltados para os "problemas de ordenação urbanística propriamente dita", compreendendo a expansão urbana, o sistema viário e o zoneamento de usos e densidades (CPEU, 1960a, p.11).

A despeito da propaganda exercida pelos profissionais do CPEU, os planos tiveram pouca efetividade prática e quase não aconteceram os desdobramentos previstos para "a continuidade do planejamento", sendo que, para a maioria dos municípios, não se passou da elaboração de Planos Preliminares. Feldman observou que as estruturas de planejamento propostas pelo CPEU não foram incorporadas nas práticas da administração municipal:

Na maioria das cidades onde as comissões são instaladas e os planos são elaborados, tanto a manutenção da estrutura do setor de planejamento como a implantação dos planos não se viabilizam. De modo geral, as comissões são dissolvidas e o arquiteto responsável pelo Plano é dispensado. (FELDMAN, 2005, p. 228).

Os planos realizados após a saída de Anhaia Mello não apresentaram grandes mudanças quanto aos argumentos que justificavam a sua importância ou quanto à estrutura do plano ou os métodos de trabalho. O processo de planejamento continuou a ser fundado nas comissões do plano e técnica, persistiu a preocupação com a "conquista da opinião pública".

No plano de Pinhal, enfatizou-se o caráter orientador do Plano Diretor, que devia deve "ser, tão somente, um arcabouço estruturador, deixando à iniciativa particular ampliar campo para arruamento e loteamento de suas propriedades, porém dentro de normas rígidas, consubstanciadas na lei de urbanismo e zoneamento" (CPEU, 1965, p. 52). O plano de Pinhal também continha, como novidade, a exigência da destinação de áreas públicas na abertura de loteamentos, a fim de prescindir da realização de desapropriações para obras públicas futuras. Note-se que o plano é anterior à promulgação da Lei Federal de Parcelamento do Solo (Lei n 6766/1979), quando isso se tornou uma obrigatoriedade em nível nacional. No plano, propunha-se que essas áreas fossem arrendadas a particulares por longos períodos de tempo, nos moldes de experiências europeias. Com relação ao município de Amparo, observou-se que foi dada menor ênfase à pesquisa, tendo sido adotados os dados disponibilizados pelo Conselho Nacional de Estatística. Birkholz considerou que "os resultados positivos do processo, além da formação de quadros técnicos, [disseram] respeito à aprovação de leis específicas de loteamento, código de obras, medidas de zoneamento, etc." (BIRKHOLZ, 1964). 


\section{O fim das atividades do CPEU}

De acordo com pesquisadores do CPEU, um dos principais motivos para o encerramento das atividades do centro foi a competição com escritórios particulares de planejamento, que levou à pressão por parte dos presidentes do Instituto de Engenharia e do IAB-SP junto ao Governo do Estado. "Não dispondo de dotações próprias para a realização de seus trabalhos, [O CPEU] valia-se dos recursos obtidos dos trabalhos de planejamento" (BIRKHOLZ \& NOGUEIRA, 1992, p. 10). Esse depoimento coincide com a análise feita por Feldman acerca do advento das empresas de consultoria que se consolidaram juntamente com a figura do arquiteto-planejador (2005, p.229).

Ao mesmo tempo, apontou-se a questão da Reforma Universitária de 1969, quando foram extintas as cátedras e a organização da pesquisa foi reformulada, inviabilizando a manutenção do Centro tal qual previsto na Lei 3.233/1955. Internamente à FAU-USP, o modo de trabalho do CPEU parece ter sido objeto de conflitos. Durante o Fórum de Debates 1968, visando uma revisão do ensino na FAUUSP, a forma de atuação do CPEU foi criticada por Vilanova Artigas, como podemos observar abaixo:

É inegável que o Centro de Pesquisas Urbanísticas (sic) transformou-se num escritório de planos para cidades do interior. Por mais que se queira justificar este fato com argumentos em torno da obtenção de verba para funcionamento, etc., a verdade é aquela acima. Isto não serve à Universidade, à FAU, e aos profissionais do urbanismo, pois abandonou quase que integralmente a sua finalidade principal - a pesquisa urbanística. A verdade é que, agora, quando se fala tanto em Grande São Paulo, quando o plano de São Paulo está sendo feito nas condições que conhecemos, nossa autoridade, a partir do CPEU é quase nenhuma para firmar princípios sadios (ARTIGAS, 2001, p. 63).

$\mathrm{Na}$ avaliação dos profissionais do CPEU, foi a partir do Fórum de 68 que o Centro entrou em sua fase descendente (BIRKHOLZ \& NOGUEIRA, 1992, p. 10).

\section{Considerações finais}

Neste artigo, buscamos sistematizar as principais concepções de Anhaia Mello acerca do planejamento territorial e apresentar sua aplicação em trabalhos práticos realizados no âmbito do CPEU, uma instituição fundada e dirigida por ele e na qual gozou de liberdade para aplicar suas ideias. A viabilização desse projeto passou por 
uma articulação política que permitiu dar a legitimidade e a sustentabilidade financeira para o Centro, através do convênio com o Departamento de Obras Sanitárias da Secretaria de Viação e Obras Públicas do Estado de São Paulo.

A história do CPEU é expressiva de uma visão de urbanismo vinculada ao planejamento territorial, segundo princípios defendidos por Anhaia Mello, que se consolidou a partir da FAU-USP. Observamos que os planos apresentavam uma estrutura que consistia, basicamente, na realização de uma pesquisa envolvendo diversos aspectos do município - urbanísticos, socioeconômicos, relativos ao meio natural, dentre outros - e de um conjunto de propostas para a área urbana e para a área rural, apresentadas separadamente. Dentre o que pode ser observado em todos os planos analisados, podemos citar: a demarcação da área urbana, a estimativa da população para um horizonte de aproximadamente trinta anos, o zoneamento, a definição de áreas prioritárias de ocupação visando controlar o espraiamento urbano, a adequação do sistema viário. Em muitos casos, os planos não tiveram a continuidade preconizada pelo próprio CPEU. Desse modo, as propostas contidas no plano foram parcialmente implementadas ou não o foram em absoluto. Conforme apresentamos neste artigo, os principais ganhos do processo de planejamento aconteciam, na visão de pesquisadores do CPEU, quando era viabilizada a aprovação de um conjunto de leis urbanísticas municipais, referentes à regulação dos loteamentos, ao código de obras e ao zoneamento.

As ideias de Anhaia Mello mantinham-se atualizadas em relação aos princípios de planejamento e de zoneamento norte-americanos (FELDMAN, 2005, p.57). Também a estruturação dos órgãos de planejamento propostos por eles - a Comissão do Plano enquanto experiência de "participação comunitária" e a Comissão Técnica (comissão staff) foram tentativas de reproduzir o processo norte-americano.

Do ponto de vista do discurso sobre o seu ideal de cidade, Anhaia Mello buscava contrapor-se ao que ele chamava de "urbanismo rodoviarista", defendendo as frentes

...das normas técnicas de planejamento e construção; e normas jurídicas de conduta social impostas pelo ordenamento legal vigente. As primeiras disciplinam a utilização do solo, o traçado urbano, as áreas livres e os espaços verdes, as edificações, o sistema viário, os serviços públicos e o que mais se relacione com a ordenação espacial e a organização comunitária; as últimas visam assegurar coercitivamente a observância das regras técnicas. Aquelas são normas-fins; estas, normas-meios (CPEU, 1960a, p.5). 
Na prática, os trabalhos desenvolvidos priorizaram uma leitura demográfica e quantitativa do território, embora afirmasse tratar-se de uma questão "qualitativa e não quantitativa", "biométrica e não geométrica". Assim, o produto dos planos acabava sendo fixar limites de populações, limites de gabaritos, limites de ocupação no terreno, área ideal de espaços verdes ou livres por pessoa, etc. Os instrumentos de ordenação urbanística propostos eram o zoneamento, a estruturação dos bairros em unidades de vizinhança, bem como um código de obras e uma "lei de loteamentos" que deveriam garantir a "ocupação lícita do solo".

Nesse artigo, analisamos, sob uma perspectiva histórica, os discursos, os procedimentos e o produto resultante do modo de planejamento desenvolvido no CPEU, ligado às ideias de Anhaia Mello acerca do urbanismo. Buscamos também identificar os agentes que estiveram à frente desse processo. Em boa parte dos municípios analisados, os planos do CPEU foram os primeiros planos realizados, inaugurando uma nova fase do planejamento municipal no Estado de São Paulo. Há que se considerar que, em um período de dez anos, foram desenvolvidos planos para cerca de quarenta municípios. Tendo em conta o porte do centro de pesquisa, trata-se de um volume significativo de planos, ainda que parte não tenha ultrapassado a "fase preliminar". Cabe observar, por fim, que a forma de trabalhar do CPEU não era um consenso dentro da própria FAU, como vemos na crítica feita por Artigas em 1968, que via como problemático o CPEU tornar-se um "escritório para a realização de planos de municípios do interior". Nesse sentido, em um contexto de consolidação do campo de Arquitetura e Urbanismo em São Paulo a partir da FAU-USP, o CPEU representa uma vertente de pensamento que circulou naquele espaço, produzindo tensões com outras visões que lá se formularam.

\section{Referências}

ARASAWA, Cláudio Hiro (1999). A Árvore do Urbanismo de Luiz Anhaia Mello. Dissertação de Mestrado. São Paulo: FFLCH.

ARTIGAS, João Batista Vilanova (2001). Fórum da FAU de 1968. In: Artigas:

Arquitecto, 11 textos e uma entrevista. Almada: Casa da Cerca.

BIRKHOLZ, Lauro Bastos (1964). Planos Diretores Municipais no Estado de São

Paulo e sua implantação. Tese de livre-docência. São Paulo: FAU-USP.

BIRKHOLZ, Lauro Bastos; NOGUEIRA, Brenno Cyrino (1992). O Centro de Pesquisas

e Estudos Urbanísticos. São Paulo: mimeo. 
CPEU (1958a). Organização e funções da Comissão do Plano Diretor nos municípios. São Paulo: FAU-USP.

(1958b). Plano Diretor de Águas da Prata. São Paulo: FAU-USP.

(1959a). Modelos de fichas de levantamento e organização de dados para elaboração de Planos Diretores Municipais. São Paulo: FAU-USP.

(1959b). Plano Diretor de Socorro. São Paulo: FAU-USP.

(1960a). Boletim Informativo para o Planejamento do Litoral Norte. No 01, São Paulo: FAU-USP.

(1960b). Boletim Informativo para o Planejamento do Litoral Norte. No 02, São Paulo: FAU-USP.

(1960c). Boletim Informativo para o Planejamento do Litoral Norte. No 03, São Paulo: FAU-USP.

(1960d). Boletim Informativo para o Planejamento do Litoral Norte. $\mathbf{N}^{\circ}$ 04, São Paulo: FAU-USP.

(1960e). Pesquisa do Litoral Norte: Relatório Preliminar - Aspectos Físicos da Ação Humana, São Paulo: FAU-USP.

(1960f). Pesquisa do Litoral Norte: Relatório Preliminar - Aspectos Historicos, São Paulo: FAU-USP.

(1960g). Pesquisa do Litoral Norte: Relatório Preliminar - Aspectos Econômicos, São Paulo: FAU-USP.

(1960h). Pesquisa do Litoral Norte: Relatório Preliminar - Aspectos Administrativo, São Paulo: FAU-USP.

(1961). Plano Preliminar de Itanhaém. São Paulo: FAU-USP.

(1963a). Elementos para o planejamento territorial dos municípios. Boletim n 01. São Paulo: FAU-USP.

(1963b). O Centro de Pesquisa e Estudos Urbanísticos e os Convênios Realizados para Planejamento das Estâncias de São Paulo. Boletim $\mathbf{n}^{\circ}$ 7. São Paulo: FAU-USP.

(1963c). Conselho de Desenvolvimento, Escritório Técnico de

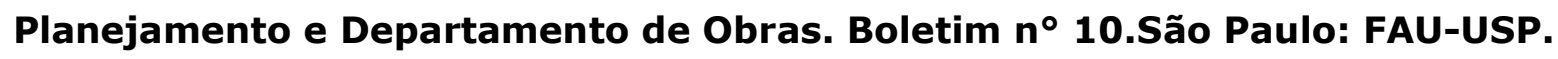
(1964a). Planejamento Territorial do Município de São José dos Campos. São Paulo: FAU-USP. (1964b). Zoneamento: classificação dos usos do solo urbano. Boletim n' 6. São Paulo: FAU-USP.

(1964c). Estância climática de Santa Rita do Passa Quatro: Relatório Justificativo 1958/1959. São Paulo: FAU-USP. 
(1965). Plano Diretor de Pinhal. São Paulo: FAU-USP. (1966). Plano Diretor da Estância de Amparo. São Paulo: FAU-USP. (1967). Plano Diretor de Bauru. São Paulo: FAU-USP. (1968). Plano Diretor de São José do Rio Pardo. São Paulo: FAU-USP. (1969). Plano Diretor de Aparecida. São Paulo: FAU-USP.

FELDMAN, Sarah (2005). Planejamento e Zoneamento. São Paulo: 1947-1972. São Paulo: Edusp/ Fapesp.

LEME, Maria Cristina da Silva (2000). A Formação do Urbanismo em São Paulo como campo de conhecimento e área de atuação profissional. Tese de livredocência. São Paulo: FAU-USP.

MELLO, Luiz Inácio de Anhaia. Um Plano Regulador para o Município de São Paulo: Orientação Planológica e Organização Administrativa. Engenharia, n.39, São Paulo, pp. 87-93.

(1954). O Plano Regional de São Paulo: uma contribuição da universidade para um código de ocupação lícita do solo (mimeo).

MEYER, Regina Prosperi (1992). Metrópole e Urbanismo: São Paulo nos anos 1950. Tese de doutoramento. São Paulo: FAU-USP.

ROLNIK, Raquel (1997). A cidade e a lei: legislação, política urbana e territórios na cidade de São Paulo. São Paulo: Nobel/Fapesp. 